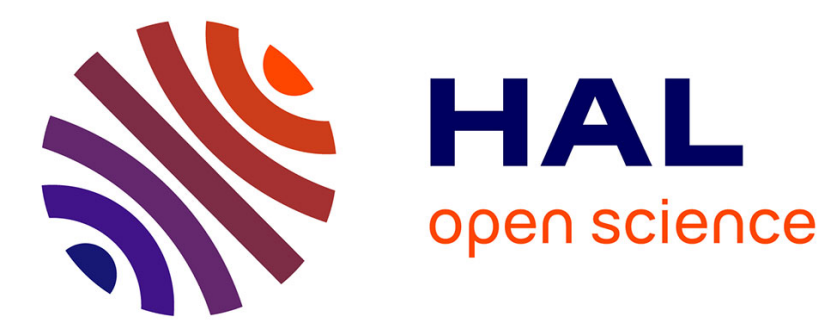

\title{
Anelastic Relaxation of Protonic Defects in M3+-Doped $\mathrm{BaCeO} 3$
}

\author{
Y. Du, A. Nowick
}

\section{To cite this version:}

Y. Du, A. Nowick. Anelastic Relaxation of Protonic Defects in M3+-Doped BaCeO3. Journal de Physique IV Proceedings, 1996, 06 (C8), pp.C8-637-C8-641. 10.1051/jp4:19968137 . jpa-00254569

\section{HAL Id: jpa-00254569 https://hal.science/jpa-00254569}

Submitted on 1 Jan 1996

HAL is a multi-disciplinary open access archive for the deposit and dissemination of scientific research documents, whether they are published or not. The documents may come from teaching and research institutions in France or abroad, or from public or private research centers.
L'archive ouverte pluridisciplinaire HAL, est destinée au dépôt et à la diffusion de documents scientifiques de niveau recherche, publiés ou non, émanant des établissements d'enseignement et de recherche français ou étrangers, des laboratoires publics ou privés. 
JOURNAL DE PHYSIQUE IV

Colloque C8, supplément au Journal de Physique III, Volume 6, décembre 1996

\title{
Anelastic Relaxation of Protonic Defects in $\mathrm{M}^{3+}$-Doped $\mathrm{BaCeO}_{3}$
}

\author{
Y. Du and A.S. Nowick \\ Materials Science Division, School of Mines, Columbia University, New-York, NY 10027, U.S.A.
}

\begin{abstract}
When perovskite-structured $\mathrm{BaCeO}_{3}$ is doped with $\mathrm{M}^{3+}$ ions (e.g., $\mathrm{Nd}^{3+}, \mathrm{Gd}^{3+}, \mathrm{Yb}^{3+}$ ) that substitute on $\mathrm{Ce}^{4+}$ sites, oxygen-ion vacancies are created for charge compensation. However, when treated in water vapor, the vacancies are replaced by protons, which take the form of $\mathrm{OH}^{-}$ions. This treatment makes the materials a good protonic conductor. Questions about the defect structure of the protons are here investigated by means of internal friction measurements, at frequencies $\sim 6 \mathrm{kHz}$. As many as three broadened Debye peaks have been found in the temperature range from $200-500 \mathrm{~K}$, the relaxation strengths of which vary as the square of the dopant concentration. Defect clusters considered responsible include the $\mathrm{M}(\mathrm{OH})$ pair and the $\mathrm{M}_{2}(\mathrm{OH})$ triplet.
\end{abstract}

\section{INTRODUCTION}

There has been much interest in protons as defects in oxides $[1,2]$. The bare proton does not remain in an oxide as a free interstitial, but combines with an $\mathrm{O}^{2-}$ ion to form a substitutional $\mathrm{OH}$ ion. Recently, it has been found that several oxides of the perovskite structure, of type $\mathrm{ABO}_{3}$, can become good hightemperature protonic conductors after protons are introduced [3-5]. Such materials can have important applications as electrolytes in high-temperature fuel cells and for steam electrolyzers and sensors [6]. The cubic perovskite unit cell is shown in Fig.1. In order to make possible the introduction of protons, the oxide must be doped with lower-valent cations that substitute on the B sites. In the usual case where B is a $4+$ ion, the dopants are of the type $\mathrm{M}^{3+}$ and carry an effective negative charge. Examples are $\mathrm{SrCeO}_{3}$, $\mathrm{SrZrO}_{3}$ and $\mathrm{BaCeO}_{3}$ doped with $\mathrm{Y}^{3+}$ and rare-earth ions. In such cases, the dopant is charge-compensated by oxygen-ion vacancies, $V_{o}{ }^{\circ}$, which have an effective double positive charge. However, treatment in water vapor allows the exchange of $V_{\circ}$ " defects by protons, according to the reaction:

$$
\mathrm{H}_{2} \mathrm{O}(\mathrm{g})+\mathrm{V}_{\ddot{o}}+\mathrm{O}_{o} \rightarrow 2(\mathrm{OH} \cdot)
$$

(Here we are using Kroger-Vink notation, in which a dot is an effective positive, and a dash an effective negative charge.)

An important question is then, to what extent the $\mathrm{OH}^{\circ}$ ions associate with the dopant ions $\mathbf{M}^{\prime}$ to form pairs or higher clusters. From Fig. 1, we can see that the simplest cluster is an $M(O H)$ pair that lies along one of the six $<100>$ directions.

The association reaction for such a pair is:

$$
M^{\prime}{ }_{B}+O H_{\dot{o}} \rightarrow P
$$




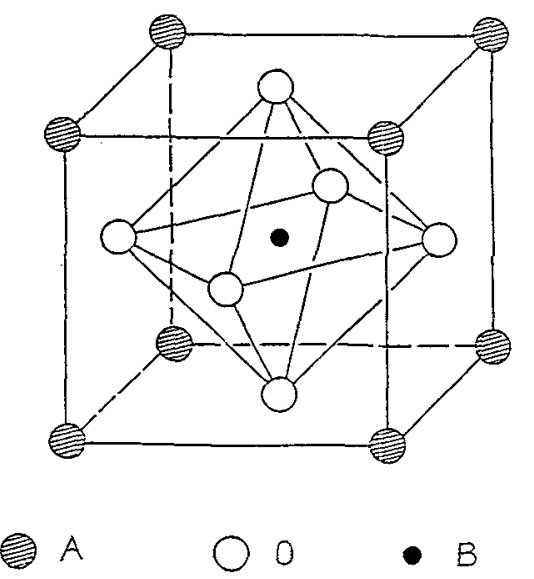

Fig. 1. Unit cell of $\mathrm{ABO}_{3}$ in the cubic perovskite structure.

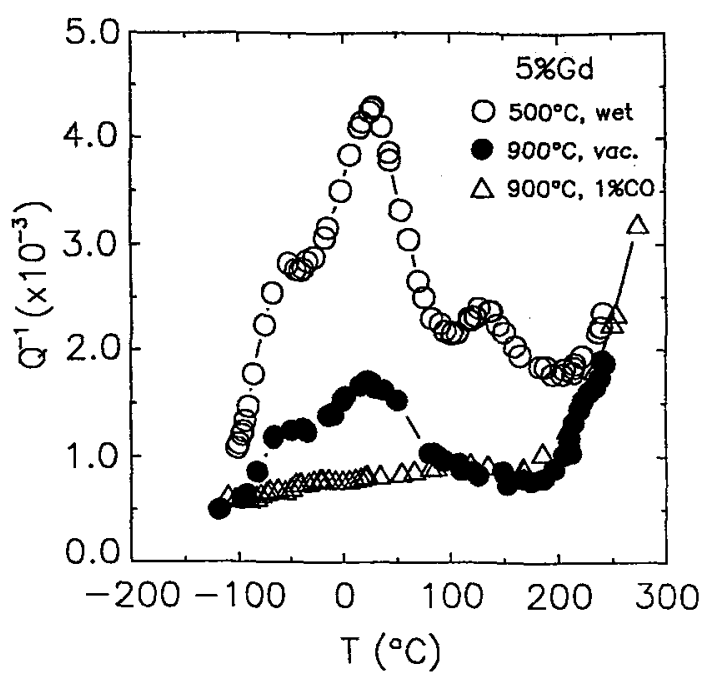

Fig. 2. Internal friction $\left(Q^{-1}\right)$ as a function of temperature for $\mathrm{BaCeO}_{3}: 5 \% \mathrm{Gd}$ following various pretreatments.

where $P$ denotes the $\mathrm{M}(\mathrm{OH})$ pair and $\mathrm{M}_{\mathrm{B}}{ }^{\prime}$ and $\mathrm{OH}_{0}$ the isolated defects. The mass-action equation for this reaction may be written:

$$
[O H][M] /[P]=K / z=[O H]^{2} /[P]
$$

where the last equality follows from the requirement of charge balance, viz., $[\mathrm{OH}]=\left[\mathrm{M}^{\prime}\right]$. Here $\mathrm{z}$ is the number of orientations of the pair while

$$
\mathrm{K}=\exp \left(-E_{A} / k T\right)
$$

in which $E_{\mathrm{A}}$ is the association energy of the pair.

There are two limiting cases of Eq.(3), depending on whether association is weak or strong. For the weak case, $[\mathrm{OH}] \cong \mathrm{c}_{0}$, where $c_{o}$ is the total dopant concentration, and therefore: $[\mathrm{P}] \propto \mathrm{c}_{\mathrm{o}}{ }^{2}$. In the strong case, $[P] \cong c_{o}$ and

$$
[O H]=\left(c_{o} / z\right)^{1 / 2} \exp \left(-E_{A} / 2 k T\right)
$$

At high dopant concentrations, one can expect to find higher defect clusters in addition to these simple pairs.

Anelastic relaxation provides an important tool for the study of defect clusters containing protons in these oxides. In previous work on $\mathrm{Nd}$-doped $\mathrm{BaCeO}_{3}$, we found a broad internal-friction peak which grew rapidly with increasing $\mathrm{Nd}^{3+}$ content [7]. Zimmerman et al. [8] also reported internal-friction peaks for $\mathrm{Yb}$-doped $\mathrm{SrCeO}_{3}$ and $\mathrm{SrZrO}_{3}$. In the present paper, we examine the effects of doping $\mathrm{BaCeO}_{3}$ with $\mathrm{Gd}^{3+}$ and $\mathrm{Yb}^{3+}$, including a study of dopant concentration dependence in the case of $\mathrm{Yb}$. In addition, we report on internal-friction measurements in complex perovskites with two different $B$-site ions of the type $A_{3} B^{\prime} B_{2}$ " $O_{9}$, where $B^{\prime}$ is divalent while $B^{\prime \prime}$ is pentavalent. Here charge compensation of protons is achieved through nonstoichiometry (i.e. by varying the $\mathrm{B}^{\prime \prime} / \mathrm{B}^{\prime}$ ratio) rather than through doping. [4] 


\section{EXPERIMENTAL RESULTS}

All samples are prepared by ceramic sintering to form bars of dimensions $\sim 20 \times 3 \times 0.6 \mathrm{~mm}^{3}$. Internal friction is measured in flexural vibration of these bars at frequencies close to $6 \mathrm{kHz}$. Details of the experimental methods have been given elsewhere [7,9].

Figure 2 illustrates the effects of various pretreatments on the internal friction of $5 \% \mathrm{Gd}$-doped $\mathrm{BaCeO}_{3}$. It shows at least three peaks following a treatment in water vapor at $600{ }^{\circ} \mathrm{C}$. These peaks are considerably reduced by treatment in vacuum (fore-pump only) and completely eliminated after treatment in a dry $1 \% \mathrm{CO}+99 \% \mathrm{CO}_{2}$ gas mixture at $900^{\circ} \mathrm{C}$.

The three peaks are referred to as the main peak $\mathrm{M}$ (at $301 \mathrm{~K}$ ), the high-temperature peak $\mathrm{H}$ (at $408 \mathrm{~K}$ ) and the low-temperature peak $\mathrm{L}$ (at $220 \mathrm{~K}$ ). They can each be fitted, in a plot versus $1 / \mathrm{T}$, to a broadened Debye peak. The fact that the peaks are lowered or eliminated by vacuum or dry gas treatments shows that all involve protons.

Similar results are obtained for $\mathrm{Yb}$ doping, except that the low-temperature peak is not well separated. Here the peaks are at $298 \mathrm{~K}$ (peak M), $418 \mathrm{~K}$ (peak H) and $248 \mathrm{~K}$ (peak L). The effect of $\mathrm{Yb}$ concentration is shown in Fig. 3 for 3, 5, and $7 \% \mathrm{Yb}$.

The case of Nd doping had been reported previously [7]. A broad peak was observed for $5 \% \mathrm{Nd}$, but it resolved into two nearly equal peaks (at 270 and $340 \mathrm{~K}$ ) at lower concentrations.

Similar studies were carried out on a number of complex perovskites such as $\mathrm{A}_{3}\left(\mathrm{Ca}_{1+\mathrm{x}} \mathrm{Nb}_{2-\mathrm{x}}\right) \mathrm{O}_{9}$ (where $\mathrm{A}$ denotes $\mathrm{Sr}$ or $\mathrm{Ba}$ ), in which charge compensation for protons comes from nonstoichiometry, i.e. $x>0$. For all such materials, no internal friction peaks were observed in the range from 200 to $400 \mathrm{~K}$, although the internal friction climbs steeply above $400 \mathrm{~K}$. An example is shown in Fig. 4 for the case of $\mathrm{Sr}_{3}\left(\mathrm{Ca}_{1.18} \mathrm{Nb}_{1.82}\right) \mathrm{O}_{9}$ pretreated in wet and dry atmospheres, respectively.

Table 1 contains a summary of the main peaks observed for $\mathrm{Yb}-, \mathrm{Gd}-$ and $\mathrm{Nd}$-doped $\mathrm{BaCeO}_{3}$. Included is the activation energy $\mathrm{E}$, calculated from the peak temperature assuming a preexponential of $10^{14} \sec ^{-1}$. Also listed are the peak height $Q_{\mathfrak{m}}{ }^{-1}$ of the broadened Debye peak, the broadening factor $\beta$ by which the peak is wider than the theoretical width calculated from $E$, and the relaxation strength $\Delta=2 \beta Q_{m}{ }^{-1}$. In addition, for the $\mathrm{Yb}$-doped sample, the ratio $\Delta / \mathrm{c}_{\mathrm{o}}{ }^{2}$ is given, showing that this ratio is nearly constant.

As shown in Fig. 2, the high-temperature peak, for which the activation energy is $\sim 0.76 \mathrm{eV}$, is very sensitive to pretreatments, disappearing more rapidly than the main peak with reduction of $\mathrm{H}_{2} \mathrm{O}$ pressure. It also varies with dopant concentration in a more complex manner than the main peak, showing the highest value for $3 \% \mathrm{Yb}$ (see Fig. 3). The low-temperature peak is not so well defined and is not well reproduced. It will, therefore, not be given detailed consideration until it is further studied.

Table 1: Main peaks for the three dopants, including $\mathrm{Yb}^{3+}$ at 3 concentrations

\begin{tabular}{|c|c|c|c|c|c|c|}
\hline Dopant & Peak T (K) & $\mathrm{E}(\mathrm{eV})$ & $\mathrm{Q}_{\mathrm{m}}^{-1} \times 10^{3}$ & $\beta$ & $\Delta \times 10^{3}$ & $\Delta / c_{o}{ }^{2}$ \\
\hline $\mathrm{Yb} \mathrm{3 \%}$ & 298 & 0.56 & 1.3 & 1.65 & 4.3 & 4.8 \\
\hline $\mathrm{Yb} 5 \%$ & 298 & 0.56 & 3.3 & 1.65 & 10.9 & 4.4 \\
\hline Yb $7 \%$ & 298 & 0.56 & 6.7 & 1.7 & 22.8 & 4.7 \\
\hline Gd $5 \%$ & 301 & 0.56 & 3.0 & 1.9 & 11.4 & - \\
\hline \multirow[t]{2}{*}{ Nd $2 \%$} & 270 & 0.51 & 0.4 & 2.1 & 1.7 & - \\
\hline & 340 & 0.63 & 0.25 & 1.8 & 0.9 & - \\
\hline
\end{tabular}

\section{DISCUSSION}

The results of this work may be summarized as follows. As many as three broadened Debye peaks have been found near $300 \mathrm{~K}$ (for $6 \mathrm{kHz}$ frequency) for variously doped $\mathrm{BaCeO}_{3}$, all of which are due to defect clusters involving protons. Similar results have also been found for doped $\mathrm{SrCeO}_{3}$ and $\mathrm{SrZrO}_{3}[8]$. 


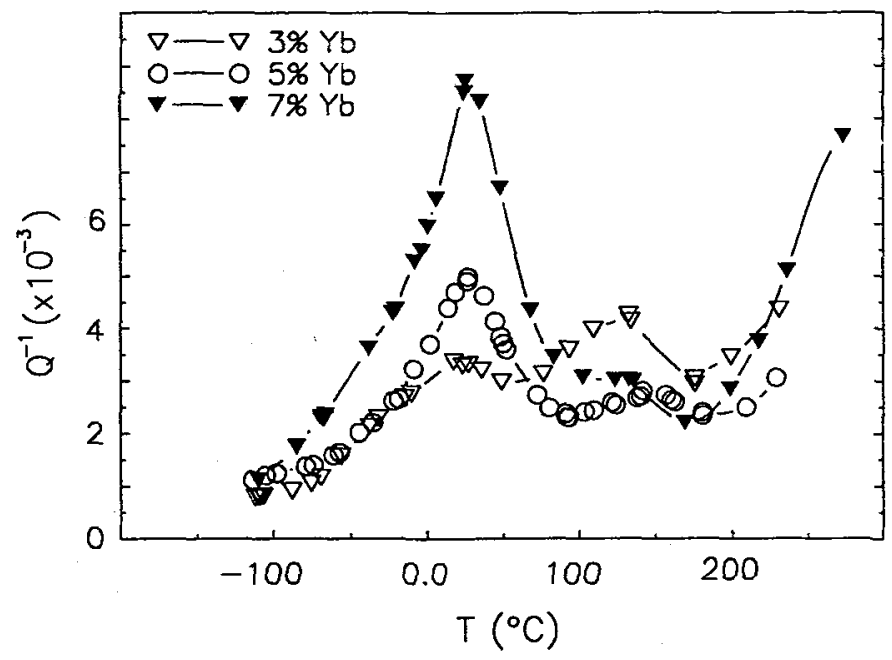

Fig. 3. Internal friction $\left(Q^{-1}\right)$ as a function of temperature for $\mathrm{BaCeO}_{3}$ doped with 3,5 and $7 \mathrm{~mole} \% \mathrm{Yb}$ following pretreatment in water vapor at $600{ }^{\circ} \mathrm{C}$.

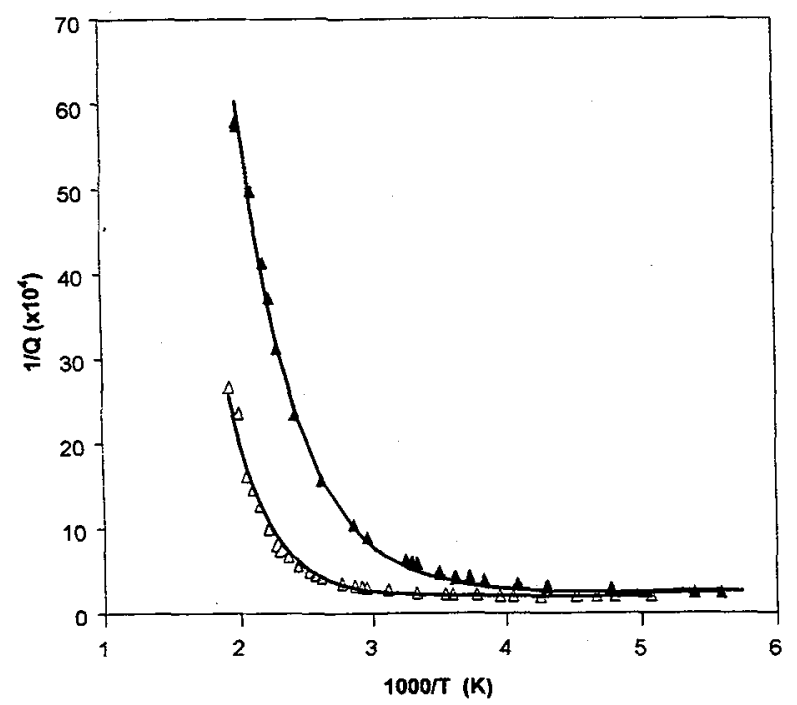

Fig. 4. Internal friction as a function of reciprocal temperature for the nonstoichiometric complex perovskite $\mathrm{Sr}_{3}\left(\mathrm{Ca}_{1.18} \mathrm{Nb}_{1.82}\right) \mathrm{O}_{9}$ pretreated in wet and dry atmospheres (upper and lower curves, respectively).

Strikingly, no such peaks have been found for complex perovskites, where the compensation for the protons takes the form of nonstoichiometry rather than dopant ions. This result strongly indicates that $\mathrm{M}^{3+}$ dopant ions as well as protons are required for the peaks. The principal peak has an activation energy close to $0.56 \mathrm{eV}$, and its relaxation strength varies with dopant concentration $c_{o}$ faster than linear, in fact, close to $\mathrm{c}_{\mathrm{o}}{ }^{2}$. Since the isolated $\mathrm{OH}$ ion has the symmetry of the lattice, all peaks must originate in clusters containing both dopants and $\mathrm{OH}$ ions. The simplest such cluster is the $\mathrm{M}(\mathrm{OH})$ pair, which possesses a 
$<100>$ orientation, as can be seen from Fig. 1. (Actually $\mathrm{BaCeO}_{3}$ has an orthorhombic structure which is slightly off cubic [10], but for present purposes we shall treat it as pseudo-cubic.)

While internal friction depends on clustered defects, information from ionic conductivity $\sigma$ is related to free defects, since $\sigma(=n e \mu)$ depends directly on $n$ the density of free carriers, in this case of unassociated protons. (Note that $\mu$, the mobility is related to the hopping rate of the protons.) A key question is whether $n$ is independent of $T$, or dependent on $T$ as in Eq.(5). The best evidence from conductivity studies suggests the former possibility and thus, that the activation energy $E_{\sigma}$ of the conductivity is simply the migration energy of the free carriers. This value is $0.55 \pm 0.01 \mathrm{eV}$ which is very close to the value of $0.56 \mathrm{eV}$ obtained for most of the main peaks (see Table 1).

If the main peak reported here is due to the $\mathrm{M}(\mathrm{OH})$ pairs, we can explain both the conductivity and internal friction behavior by assuming that the limit of weak association applies. (See the Introduction, above Eq.(5).) For in this case, we obtain $n \equiv[\mathrm{OH}]$ independent of $\mathrm{T}$ while $\Delta \propto[\mathrm{P}] \propto \mathrm{c}_{0}{ }^{2}$. It is also understandable that the activation energy $E$ for relaxation of these pairs will be close to $E_{\sigma}$, the value for hopping of free protons. In addition, from the relaxation strength $\Delta$ we can calculate $\delta \lambda$, the appropriate elastic dipole strength [11]. Thus, if we assume for $5 \%$ dopant that the concentration of pairs is $\sim 0.5 \%$, we obtain a value $\delta \lambda \sim 0.08$. Such a value is somewhat large, but still in a reasonable range [11].

More complex defect configurations are also required to explain the other peaks as well as the broadening of the main peak. An interesting candidate is the $\mathrm{M}_{2}(\mathrm{OH})$ triplet. Here an $\mathrm{M}_{2}$ pair has two effective negative charges and, therefore, has a strong attraction to an $\mathrm{OH}$ defect. It is, therefore, reasonable to assume almost complete association of this defect. Since the concentration of $M_{2}$ pairs is $\propto c_{o}{ }^{2}$, we then obtain a concentration of such triplets proportional to $c_{o}{ }^{2}$. However, the $M_{2}$ pair may have a strong affinity for any residual $V_{0}$ " defects (see Eq.(1)), thus making the concentration dependence of $\mathrm{M}_{2}(\mathrm{OH})$ triplets more complex.

The difference in behavior of the three dopants $\left(\mathrm{Gd}^{3+}, \mathrm{Yb}^{3+}\right.$ and $\left.\mathrm{Nd}^{3+}\right)$ may be related to the differences in their ionic radii, which affects the association energy, $E_{A}$, as well as $\delta \lambda$. While all three dopants have ionic radii larger than that of $\mathrm{Ce}^{4+}, \mathrm{Nd}^{3+}$ has the largest ionic radius and in fact behaves somewhat differently from the other two with regard to its internal friction peaks.

In conclusion, these internal friction studies show that substantial clustering occurs between protons and dopant ions in doped $\mathrm{BaCeO}_{3}$.

\section{Acknowledgments}

The authors are grateful to the U.S. Department of Energy for support of this work.

\section{References}

[1] Glasser L., Chem. Rev. 75 (1975) 21-65.

[2] Norby T., "Hydrogen Defects in Inorganic Solids", Selected Topics in High Temperature Chemistry, O. Johannesen, Ed. (North Holland, Amsterdam, 1989) pp. 101-142.

[3] Iwahara H., Esaka T., Uchida H. and Maeda N., Solid State Ionics 3/4 (1981) 359.

[4] Nowick A. S. and Du Y., Solid State Ionics 77 (1995) 137-146.

[5] Bonanos N., Knight K. S. and Ellis B., Solid State Ionics 79 (1995) 161-170.

[6] Iwahara H., Solid State Ionics 77 (1995) 289-298.

[7] Du Y., J. Phys. Chem. Solids 55 (1994) 1485-1490.

[8] Zimmermann L., Bohn H. G., Schilling W. and Syskasis E., Solid State Ionics 77 (1995) 163-166.

[9] Liu J. F. and Nowick A. S., Solid State Ionics 50 (1992) 131-138.

[10] Knight K. S. and Bonanos N., Solid State Ionics 77 (1995) 189-194.

[11] Nowick A. S. and Berry B. S., Anelastic Relaxation in Crystalline Solids (Academic Press, New York, 1972) Chapters $8-11$. 